\title{
Reconfiguring the Corporate and Commons: Mobile and Online Activism as a Form of Socio-technical Design
}

\author{
Constance Kampf \\ Business \& Social Sciences, Aarhus University, Aarhus, Denmark \\ cka@asb.dk
}

\begin{abstract}
This paper describes a model for understanding how digital activists contribute to (re)defining the ways in which socio-technical interactions are (re)designed at the Macro-level. This macro level is explained in three parts1) the cultural production of a new form of practice, 2) an active, contested knowledge process, and 3 ) as producing knowledge about the interface between society and business. Two kinds of digital activists are examined-critical digital activists and activists from within the system.
\end{abstract}

Keywords: Socio-Technical Design, Culture, Knowledge.

\section{Introduction}

What is digital activism and why does it matter? Since the Lotus Marketplace and Clipper Chip online protests [1], technology has begun to shift the balance of power towards consumer activists who are able to use it effectively to interrupt product development and suggest changes for corporate strategy. With critically focused activists such as Wikileaks, the hacker's group Anonymous, and digital artist activists such as Ubermorgen [2], technology is being used to engage with power structures and shift the balance of power between the corporate and the commons.

Both critical Digital activism and "activism from within the system" can be seen as constituting a force for (re)design of social technical interactions. [3] calls for two levels in our understanding of socio-technical design, a micro level focused on user level interaction, and a macro-level focused on society level interactions. These society level interactions between organized groups of activists and corporations work to shift the attention of business from itself and its own goals to surrounding issues.

This paper focuses on discussing these two approaches to Internet activism as emerging forces working to shape and shift the balance of power and the face of technology based interactions between corporations and the commons as a form of sociotechnical design. Under-standing these two approaches to Internet activism helps demonstrate ways in which activists towards business engage in socio-technical (re)design at the macro level. 


\section{Method}

This paper uses argument and example to lay out a theoretical frame-work for understanding how different forms of online activism provide forces shaping socio-technical (re)design at the macro level. Both primary and secondary data are used to point out patterns among cases of Internet activism, and reflect on their implications for explaining how different kinds of activism function as a force shaping the (re)design of socio-technical interactions. Primary data consists of social media postings in Blogs, YouTube, Facebook as well as websites collected from 2008-present. Primary data is focused on an NGO — CarrotMob, and a B corporation, the Good Guide.

This primary and secondary data is approached through a multidisciplinary lens combing sociotechnical design, organizational theory and sociological concepts. These concepts draw from two distinct levels of understanding the interaction between people and technology. First, from a workplace level, applying socio-technical design and organizational theory we can find a perspective on knowledge that is both socio-technical and process oriented in nature. Adding a more general level, that of society, we can expand that perspective to include an epistemic or knowledge producing space that affects and interacts with culture at the societal level.

This lens draws on the following concepts. From a traditional workplace focused perspective on socio-technical design, Suchman et al [4] describe systems development as cultural production of new forms of practice. From the field of Management, Blacker argues for under-standing knowledge as an active process in a culturally located system [5]. According to Blackler, this process is contested, provisional, and pragmatic. In the case of a Macro approach to Socio-Technical design, this culturally located system can be understood as an epistemic, or knowledge producing. Knorr Cetina puts forward the notion of a general knowledge culture in which specific knowledge processes are embedded [6], from the field of sociology. She uses the term "epistemic" or knowledge-producing to describe a knowledge culture, focusing on the ways in which knowledge is produced and reproduced through what she terms "epistemic circuits" connecting actors and technologies. We can link these three perspectives together for understanding a macro level of socio-technical design. This macro level can be constructed through examining Blackler's active, contested knowledge processes as part of a global epistemic culture following Knorr Centina's sociological frame of reference, in which activists are engaging with social and mobile media to produce contested, provisional and pragmatic knowledge about the interface between society and business. This use of social and mobile media can be informed by Suchman et al's connection between technology and cultural production to a global, macro-level for socio-technical design [3].

To operationalize this multidisciplinary lens, Critical digital activism and "Activism from within the system" will be examined through 1) the cultural production of a new form of practice [4]; 2) as an active con-tested knowledge process [5]; and 3) as producing knowledge about the interface between society and business $[3,6]$. These 3 aspects work together to demonstrate how each type of activism can be understood as a force for (re)design of socio-technical interactions through linking together practice, process and the larger picture of the interface between society and business. 


\section{Critical Digital Activism as a Force for (re)design of Socio-technical Interactions}

Critical digital activism reconfigures the commons and the corporate in unexpected ways. The technologies of email, websites, and social and mobile media open up spaces for critics of business strategy to be heard and gather followers with global reach.

\subsection{The Cultural Production of Reach in the Public Critique of Business Strategy}

In the late 1980s, the movement of email, bulletin boards, and discussion lists from the workplace to society enabled a shift in the ability for large groups of protesters to communicate with each other and companies. An important type of protester was the consumer activist. Lotus Marketplace is an example of a product that was widely protested through these new channels [1]. In the end, consumer actions led to change in company strategy and the product was cancelled before it reached the market.

Another type of critical digital activist is the artist-activist. The artist-activists do not always begin as activists, but can react to the pressures of companies when they feel the company is inappropriate. An example of this can be seen in the etoy war, arguable the most expensive art performance in history. The digital artist activist group etoy.com was legally pressured by a U.S. new technology startup, eToys.com to stop using their domain name because it was too similar to etoys.com and etoys.com customers who mistyped the URL were offended by etoy.com content. First the company sent them a request for their domain name, and when it was refused, the company eToys.com went to court and won an injunction preventing the digital artist group etoy from using their domain. The group was forced by US legal action to comply, and they felt it was unjust because they had owned the domain etoy and built their brand in Europe before the company eToys.com was started. In reaction, they opened a new domain, Toywar.com, and started "involving the enemy in an insane ToyNam situation." [2]. The new domain, Toywar.com, supported a game that awarded points for actions that lowered Etoys.com stock. The artists recruited 1799 hackers to play the game. The result of this art performance was bankruptcy for eToys.com, which was sold at a loss of billions of dollars [2]. Here, the artists not only affected the business strategy, but they felt attacked by it, and so they coordinated a responding attack. The reach of these artists enabled them to affect eToys.com in an unprecedented manner.

\subsection{Critical Digital Activism as an Active, Contested Knowledge Process}

In the cases of Lotus Marketplace and the eToy war, the activists engaged in communicating ideas which addressed a contested boundary between business and society. In the case of Lotus Marketplace, the product itself was selling personal information that was already available publicly, but packaged in a CD-ROM format that (for that point in time) would make it easier for marketers to target consumers. In the late 1980s, 
consumers were upset about a product that they understood would affect their privacy. Thus, protesting Lotus Marketplace as a product could be understood having roots in an active discussion. Gurak describes the discussion as taking place over a period of several months, during which computer specialists and consumers engaged in technical arguments about the product. She describes postings as having "a range of functions: to inform, to debate the protest, to debate the product, to mobilize, to divulge "secret information" and to discuss other privacy related issues." Thus, the activism had roots in a contested discussion about the nature of privacy at the interface of business and society [1, p.27].

On the other hand, the digital activists focused on issues of ownership and legal rights, contesting the perspective of the corporation and the US courts by statements on their website telling the story, as well as by actions of creating a space where the corporation was not prioritized because of its' resources, but rather reconfigured to become the enemy of free art and free speech. Here, the contested understandings of the situation were not discussed as much as enacted in the art performance, described as a virtual "ToyNam" by the artists [2]. Because the force of courts had set up the knowledge that a company has the right to take away a domain that had been held by another group before the company was created, the artists chose to act out their disagreement rather than discuss it, and within the framework of the game offered different options for supporting "toy soldier" hackers to lower the stock of Etoy.

Both of these cases demonstrate that activism occurs within an active and contested space, and the duration of the Lotus Marketplace discussions over a period of several months, as well as the duration of the ToyNam performance over about a year indicate that the activism was not a single effort, but rather an ongoing, engaged process.

\subsection{Critical Digital Activism as Producing Knowledge about the Interface between Society and Business}

Both Lotus Marketplace and the ToyNam art performance by the etoy artist collective offer examples of activists focusing on the interface of business and society as it is shaped and (re)shaped by technology. Each case focuses on a different key issue. For the Lotus Marketplace product, privacy and consumer perception of privacy became a key issue. At the time, the knowledge produced around privacy was communicated through then current technology: usenet groups, bulletin boards, MOOs and MUDs, and email. This knowledge addressed but did not resolve issues related to privacy, and we are still dealing with them in different forms today. For the ToyNam art performance, the issue was virtual domain ownership - do companies have the right to interfere with previously owned domains because it can affect their business? The response of the artist activists set a clearer boundary by creating the knowledge that a group of unhappy digital artists and their supporters had the ability to affect the success of a large and well funded business which had, in effect, attacked the digital artists' brand.

Both of these issues - issues of privacy and domain ownership, can be seen as cultural in nature. The ways in which people choose to question or accept privacy standards become cultural norms over time. The question is to what extend are we 
drawn into adapting our cultural practices to fit the needs of the business? For example, recent Google and Facebook practices have taken the notion of transparency and turned it over towards the consumer, setting up consumer transparency as a key issue rather than consumer privacy.

\section{4 "Activism from within the System" as a Force for (re)design of Socio-technical Interactions}

"Activism from within the system" reconfigures the commons and the corporate around a principal focus or single topic approach, and is designed to push an agenda in way that creates a "win-win" situation for both business and society. These digital "activists from within the system" use technology to facilitate changes within the current corporate-commons balance. We will examine two examples: CarrotMob, an NGO led by Brent Schulkin, and Good Guide, a B-Corporation led by Dara O'Rourke. These organizations use technology and social media to build awareness in the commons around the issues of Corporate Social Responsibility (CSR) and sustainability, and put pressure on corporations to change by engaging them in win-win scenarios.

\subsection{The Cultural Production of Corporate Social Responsibility in the Public Critique of Business Strategy}

Like the critical activists, activists from within are also engaged in using or appropriating technology for cultural production. In this case though, they go beyond the cultural production of reach already established by earlier digital activist movements to the cultural production of CSR. The framework for CSR is contested, and corporations work at sensegiving [7] through their communications as much as NGOs, and government bodies also work to define it. In producing cultural norms for CSR, CarrotMob and Goodguide each focus on a different definition. For CarrotMob, the cultural production of CSR is done using video campaigns in YouTube to create a dialog with local business owners and activists around sustainability issues. The key video of the organization is a cartoon that shows business as polluting the environment, and not responding to government, but rather to people who have pooled their resources enough to gain corporate interests [8]. The goal of the organization is to create a new cultural norm or resource through the activity of organizing purchases and negotiating with businesses to engage in CSR such as reducing their environmental footprint. These issues engage with different cultural norms in the different locations of the CarrotMob events. For example, the CarrotMob event in Jönköping, Sweden, focuses on purchasing fair trade goods in local grocery stores [9]. In contrast, the CarrotMob event in Eugene, Oregon has a number of videos that focus on reducing waste, energy use, and engaging a local supply chain in local coffee shops [10]. There are currently 328 videos from around the world that show aspects of CarrotMob events. Each of these videos is localized to create a cultural production of the practice of coordinated purchasing appropriate to the local cultural context. 
The Good Guide also engages in a different kind of cultural production of CSR. It focuses on the coordination and interpretation of scientific data about products to rate them with respect to three categories of CSR - health, environment and community. The Good Guide is unique in its' focus on health as a component of CSR for products. To create this type of activism from within the system, the Good Guide is a for profit company with a NGO style mission. Thus, companies hire Good Guide to feature their products in Good Guide's information system. This system is available as a database from their website, as well as an iPhone app which scans in product bar codes at the point of purchase. The Good Guide app then shows their rating system for each of the their three key categories, allowing the user to find more information about the product's ingredients, as well as keep track of how socially responsible their purchases are. The rating system is a 10-point scale, with 4 shades of color to remind consumers about their choices. These shades are green for products that are good, and shades of brown, orange and red for products that have scientific data that demonstrate issues in one of the three areas. Thus, by using the Good Guide smart phone app or database to evaluate products before purchase, consumers enact responsible purchasing, which then ostensibly puts pressure on companies to produce more responsible products.

\section{2 "Activism from within the System" as an Active, Contested Knowledge Process}

Both CarrotMob and GoodGuide offer different approaches to opening up conversations around CSR. For CarrotMob, these different approaches to CSR knowledge can be seen in the video content, with different sponsors emphasizing various aspects of CSR from fair trade products, to waste reduction and local supply chains, to workers rights. Although the CarrotMob web presence does not specifically offer a space for discussing issues related to sustainability, the format for Carrotmob events is open enough to allow organizers to focus in on issues, which they find important and relevant in their context. Thus, the collection of CarrotMob videos operates as a contested knowledge process in which consumers from around the globe are engaging in building definitions of CSR appropriate to their local contexts. For GoodGuide, these approaches focus on coordinating and organizing scientific research in their database, as well as encouraging consumers to interact with government regulators with issues related to health. In the website database, consumers are offered the ability to recommend, suggest avoiding, and/or comment on their experience with each product. This opens up a formal space for dialogue and allows for an active, contested knowledge process to build knowledge about each product while including multiple perspectives.

\section{3 "Activism from within the System" as Producing Knowledge about the Interface between Society and Business}

CarrotMob and GoodGuide both work to produce knowledge about how consumer action and dialog affects business strategy in win-win activist scenarios. In addition, they work to produce knowledge about ways in which consumers can engage in 
consuming with responsibility in order to encourage companies to offer opportunities for responsible/sustainable consumption. Thus, the interface between society and business in these cases focuses on sharing knowledge about products, and brings a critical perspective to consumption. The idea behind this type of activism is then, that this communication loop between consumers explaining their strategy for sustainability, or their needs for a product that protects their health as well as the community and environment and corporations will lead to (re)definition of CSR as well as a (re)definition of the roles for consumers and business to engage in co-producing CSR through their actions, which in turn affects the possibilities for knowing how consumers and businesses should interact at the interface between society and business.

\section{Conclusion}

In conclusion, this model for understanding the effects of digital activism on culture can be seen through the overall idea of a Macro-level for socio-technical design. This Macro-level focuses on cultural changes in society. It can be operationalized through the three aspects used to examine digital activists-1) cultural production, 2) an active, contested knowledge process, and 3) producing knowledge about the interface between society and business. These three aspects of a Macro-level for sociotechnical design were examined using examples from two kinds of digital activistscritical activists and "activists from within". The activists in both categories examined here followed similar processes, which can be understood as a macro level for socio-technical design. Each group of activists worked towards engaging in cultural production, an active contested knowledge process and producing knowledge about the interface between society and business. By following the Macro-level for sociotechnical design, one can see a way of explaining how technology affects our possibilities for action, activism, and engaging in both processes of creating knowledge and producing culture. In order to develop a more nuanced understanding of a macro-level for socio-technical design, connecting these three aspects to definitions of culture in global contexts would be a useful next step.

\section{References}

1. Gurak, L.: Persuasion and Privacy in Cyberspace: The Online Protests over Lotus MarketPlace and the Clipper Chip. Yale University Press (1997)

2. Kampf, C., Cox, G.: Using Digital Art to make the tensions between Capital and Commons Transparent: Innovation in shaping knowledge of Internet business practices as a form of cultural knowledge. In: Cultural Attitudes Towards Communication and Technology Proceedings, Aarhus 2012. Murdoch University Press (2012),

http: / / blogs .ubc.ca/catac/proceedings / proceedings-2012 /

3. Kampf, C.: Revealing the Socio-technical Design of Global e-Businesses: a case of digital artists engaging in radical transparency. International Journal of Sociotechnology and Knowledge Development 4(4) (2012)

4. Suchman, L., Bloomberg, J., Orr, J.E., Trigg, R.: Reconstructing Technologies as Social Practice. American Behavioral Scientist 43, 392 (1999) 
5. Knorr Cetina, K.: Culture in global knowledge societies: knowledge cultures and epistemic cultures. Interdisciplinary Science Reviews 32(4) (2007)

6. Morsing, M., Schultz, L.: Corporate social responsibility communication: stakeholder information, response and involvement strategies. Business Ethics, A European Review 15(4), 323-328 (2006)

7. Gioia, D.A., Chittipeddi, K.: Sensemaking and Sensegiving in Strategic Change Initiation. Strat. Mgmt. J. 12, 433-448 (1991)

8. Shulkin, B.: How organized purchasing can change business. YouTube Video (2008), http: / / www . youtube.com/watch?v=AkGMVQ18_jI (accessed March 1, 2013)

9. Rättvis handel Jönköping. Carrotmob premiers in Jönköping (2010), http: / /www.youtube.com/watch?v=pZ_XIrn2PQU (accessed March 1, 2013)

10. Eugene Carrot Mob (2990). Eugene CarrotMob Teaser, http: / / www . youtube.com/watch?v=pZ_Xlrn2PQU (accessed March 1, 2013) 